\title{
Do Programa de Volta para Casa à conquista da autonomia: percursos necessários para o real processo de desinstitucionalização
}

| 1 Sheila Silva Lima, ${ }^{2}$ Sandra Assis Brasil |

Resumo: O Programa de Volta para Casa (PVC) visa contribuir para a inserção social de pessoas que estiveram internadas ao menos dois anos ininterruptos em hospital psiquiátrico. A pesquisa objetivou identificar o impacto desse programa, assim como do Benefício de Prestação Continuada (BPC), para a efetivação das ações de desinstitucionalização. Durante seis meses foram utilizadas técnicas de observação participante em duas Residências Terapêuticas localizadas em Salvador-BA, incluindo conversas informais com profissionais desses espaços e do Centro de Atenção Psicossocial (CAPS) que os administrava. Também foi realizada pesquisa documental em documentos oficiais referentes ao PVC. Os dados observados no cotidiano das residências sugerem que há um processo de burocratização e pouca autonomia em torno do uso do dinheiro, além de faltarem estratégias efetivas para a produção do empoderamento dos beneficiários do PVC. Observase a necessidade de um maior investimento em educação permanente dos profissionais, bem como de um significativo fortalecimento das chamadas "estratégias de desinstitucionalização" previstas pela Rede de Atenção Psicossocial.

> Palavras-chave: institucionalização; Saúde Mental; política de saúde; desenvolvimento de programas; desinstitucionalização.

\author{
1 Psicóloga, residente em \\ Saúde Mental pelo Programa \\ de Residência Multiprofissional \\ em Saúde do Departamento \\ de Ciências da Vida da \\ Universidade do Estado \\ da Bahia. Salvador, Brasil. \\ Endereço eletrônico: lima \\ ssheila@gmail.com \\ ${ }^{2}$ Doutoranda em Saúde Pública, \\ Instituto de Saúde Coletiva, \\ Universidade Federal da Bahia. \\ Salvador, Brasil. Endereço \\ eletrônico: sanbrasil@gmail.com
}

Recebido em: 29/11/2012 Aprovado em: 13/01/2014 


\begin{abstract}
Não queria ficar sozinho no quarto branco que cheirava a Qboa/ disse que preferia voltar para casa/ que da janela da casa ele via a rua/ que na rua sempre alguém passava/ a calçada é que ia vê-lo ir-se embora/ não aquele corredor asséptico e malcheiroso.

Vera Lúcia de Oliveira
\end{abstract}

A Reforma Psiquiátrica Brasileira, instituída pela Lei no 10.216/2001, é interpretada de maneiras distintas. Para uns, resume-se a uma reestruturação do modelo assistencial psiquiátrico; para outros, privilegia as transformações sociais em detrimento da clínica (AMARANTE, 2001). No presente estudo, endossando a utopia basagliana, considera-se a Reforma Psiquiátrica um processo social dotado de complexidade, que está em constante movimento, e que por isso mesmo pertence à ordem do permanentemente inacabado, na qual se busca a constante transformação da realidade para a superação de seus limites e contradições.

Basaglia (1996) chama a atenção para a necessidade da realização de ações de desinstitucionalização daqueles que estão há muito tempo asilados. Tal processo produz transformações no campo do saber e das instituições, não se restringindo à reestruturação técnica dos serviços ou de terapêuticas modernas (AMARANTE, 2001). Essa concepção de desinstitucionalização difere da de desospitalização, uma vez que não se restringe à mera saída da pessoa com transtorno mental da instituição psiquiátrica (AMARANTE, 1996).

O Ministério da Saúde aponta que o tripé indispensável para a efetivação da desinstitucionalização é formado pelo Programa de Volta Para Casa (PVC), junto com o Programa de Redução de Leitos Hospitalares de Longa Permanência e os Serviços Residenciais Terapêuticos (SRT) (BRASIL, 2008). O PVC é regulamentado pela Lei $\mathrm{n}^{\circ} 10.708 / 2003$ e consiste no pagamento do auxílioreabilitação psicossocial. Seu objetivo é

[c] ontribuir efetivamente para o processo de inserção social dessas pessoas, incentivando a organização de uma rede ampla e diversificada de recursos assistenciais e de cuidados, facilitadora do convívio social, capaz de assegurar o bem-estar global e estimular o exercício pleno de seus direitos civis, políticos e de cidadania (BRASIL, 2003, p. 01).

Esse dinheiro, portanto, precisa ser utilizado com o fim de acompanhar o beneficiário no processo de reabilitação psicossocial (BRASIL, 2003). O valor 
do benefício, que em 2003 era equivalente ao do salário mínimo, 240 reais, poderia ser reajustado pelo poder executivo, de acordo com a disponibilidade orçamentária. Porém, atualmente, a quantia paga é de apenas 310 reais. De acordo com o manual do programa, podem receber o benefício as pessoas com transtornos mentais egressas de hospitais psiquiátricos que estiveram internadas ininterruptamente por dois anos ou mais (BRASIL, 2003).

Em dezembro de 2011, foi instituída a Portaria $n^{\circ} 3.088$, que estabelece a Rede de Atenção Psicossocial. Entre os componentes dessa rede, encontram-se as Estratégias de Desinstitucionalização, sendo reafirmado como uma delas o PVC, considerado uma política pública de inclusão social que visa contribuir para o processo de desinstitucionalização e fortalecê-lo (BRASIL, 2011). Contudo, a desinstitucionalização não é referida enquanto objetivo na lei que institui o PVC, nem no seu manual, sendo utilizadas palavras como reinserção, inserção, habilitação, reintegração e reabilitação. Importante ressaltar que os termos citados não se equivalem, havendo inclusive uma diferença de posição teórico-ideológica no que se refere a seus usos.

A ideia de reabilitação, por exemplo, se refere ao trabalho necessário para fazer o sujeito recuperar as habilidades que foram prejudicadas pela doença. Aponta, portanto, para uma ação posterior à cura ou tratamento. Contudo, não haveria para a clientela psiquiátrica uma separação entre tratamento e pós-tratamento (TENÓRIO, 2001a):

\footnotetext{
Adjetivada como reabilitação psicossocial, a intervenção visa [...] permitir ao paciente "alcançar seu nível ótimo de funcionamento independente na comunidade", a melhoria da "competência individual", as "habilidades sociais individuais", a "competência psicológica", o "funcionamento ocupacional", a "autonomia" e a "possibilidade de autodefesa" [...] [O] paradigma da reabilitação psicossocial também desloca o tratamento da doença para a existência, porém mantém um caráter pedagógico, de educação para a vida social (TENÓRIO, 2001a, p. 122).
}

A noção de reinserção social também é problemática, uma vez que, mesmo estando dentro de um hospital psiquiátrico, o sujeito se encontra dentro da sociedade, embora de forma marginal e perversa. As pessoas com transtornos mentais também podem recorrer ao Benefício de Prestação Continuada (BPC), assegurado pela Constituição Federal de 1988. Estão previstas em seu artigo 203, entre outros objetivos, a habilitação e reabilitação das pessoas portadoras de deficiência e a promoção de sua integração à vida comunitária. Nesse artigo, 
consideram-se portadores de deficiência todos que aqueles com deficiência física, mental ou doença mental.

Há uma literatura ainda incipiente sobre o PVC e suas repercussões. Ribeiro (2006) aponta que os moradores das residências terapêuticas (RT) que recebem esse benefício demonstram melhoria no nível de interesse em adquirir e poder trocar objetos, o que lhes proporciona maior autonomia. Contudo, a importância dada a esse programa pelos profissionais ainda é baixa. Lima (2008) identifica que os profissionais conhecem pouco o programa e não conseguem enxergar seu potencial para ações de desinstitucionalização.

Lima (2008) e Campos (2008) discutem que muitas vezes o dinheiro adquirido é gerenciado pela família ou pelo serviço de saúde. Isso ocorre porque se tende a considerar que o recurso será gasto com "besteiras" ou que os beneficiários estão cronificados a ponto de não apreender a existência do mesmo. De modo geral, os autores concluem que existe certa incoerência entre a proposta de reabilitação social e sua execução, uma vez que são ausentes trabalhos voltados especificamente para esse propósito.

No que diz respeito aos SRTs propriamente ditos, há trabalhos que discutem não apenas a situação de implantação desse dispositivo no Brasil (FURTADO, 2006), mas também sua importância para o processo de desinstitucionalização (MÂNGIA, 2002), considerando sua relevância para a reconstrução das relações dos usuários com a cidade. Furtado (2010) chama a atenção para a necessidade de se avaliar o modo como as pessoas com sofrimento mental, moradores ou não de SRT, constituem suas habitações e inserção social a partir dos elementos estruturais da moradia.

Há um vasto número de produções teórico-conceituais acerca dos processos de institucionalização e seus efeitos iatrogênicos (GOFFMAN, 1974; BIRMAN, 1980; BASAGLIA, 1985; TENÓRIO, 2001b; SILVA, 2001; LOUGON, 2006). Do mesmo modo, há certo consenso na literatura (LOBOSQUE, 1997; TENÓRIO, 2001b; DIMENSTEIN, 2004; LANCETTI, 2009; PANDE; AMARANTE, 2011) de que as práticas em saúde mental devem promover a desinstitucionalização, o resgate da cidadania e a conquista da autonomia das pessoas com transtornos mentais.

O grande desafio se encontra no modo como tais ações devem ser desenvolvidas para que esses objetivos sejam concretizados. A literatura atual acerca da 
desinstitucionalização tende a repetir as concepções teóricas dos autores clássicos da área, sendo necessário um maior número de produções que apontem para o cotidiano minucioso de tais práticas, seus limites e desafios, e o modo como se deve manejá-las. Tal contexto assinala a necessidade da ampliação do quantitativo de trabalhos etnográficos e de observação participante, além de relatos de experiência que discutam investimentos emancipatórios no campo da saúde mental.

Este estudo centra-se na utilização do dinheiro adquirido por meio do PVC e do BCP, envolvendo a análise minuciosa de situações e interações do dia a dia que possam contribuir para a autonomia dos que moram em SRT. Objetiva-se identificar as contribuições do BPC e PVC na vida dessas pessoas, para que a desinstitucionalização ocorra de forma efetiva. Compreende-se que a autonomia está na base do processo de desinstitucionalização, não sendo, contudo, uma meta fixa. Ao contrário, quando se trata de sujeitos com transtornos mentais, é preciso renunciar às comparaçōes e exigências de eficácia e desempenho e levar em consideração as novas possibilidades presentes a partir de outro modo de subjetivação, incluindo a participação em graus variados e a expressão de múltiplas e distintas subjetividades. $\mathrm{O}$ conceito de autonomia aqui endossado está, portanto, atrelado ao de liberdade.

\section{Metodologia}

Os beneficiários que contribuíram para esta pesquisa residiam em duas RTs localizadas em um bairro residencial de Salvador-BA, em uma região onde é possível contar com espaço de lazer, inclusive em decorrência da proximidade com a praia, além de outros dispositivos que servem à comunidade, como supermercados, padarias, lanchonetes, farmácias etc. As RTs são administradas pela Secretaria Municipal de Saúde de Salvador, sendo que um Centro de Atenção Psicossocial (CAPS) é responsável pela atenção à saúde mental e por atividades de reinserção social dos moradores, bem como pelo apoio aos cuidadores.

Cada residência visitada servia como moradia para seis pessoas. Uma RT era específica para abrigar mulheres e a outra, homens, totalizando 12 moradores. Desse total, três eram beneficiários do PVC (duas mulheres e um homem), sete recebiam o BPC (duas mulheres e cinco homens) e duas mulheres não recebiam nenhum benefício. De acordo com informações de alguns profissionais do CAPS, isso ocorria devido à ausência de documentação civil. 
Foram realizadas visitas semanais durante seis meses, inclusive durante o período noturno. Os dados utilizados são oriundos da observação participante do cotidiano das RT, que foram registrados em diários de campo ao longo das visitas. Além disso, ocorreram conversas informais com os beneficiários, profissionais do CAPS e das RTs, a fim de que as observações pudessem ser complementadas. Outra estratégia utilizada foi a pesquisa documental de informaçôes oficiais do programa.

Sobre a realização dos diálogos informais, é preciso esclarecer que a vivência dentro da RT demonstrou a impossibilidade de realização de entrevistas, ainda que abertas. Alguns moradores não apresentavam linguagem verbal, ou a apresentavam de forma bastante dificultada.

Considerando o grau de cronificação da maior parte dos moradores, foi necessário o estabelecimento prévio de um vínculo entre a pesquisadora e o grupo, a fim de que a comunicação pudesse ocorrer sem proporcionar tanta ansiedade aos moradores. Esse vínculo se construiu de forma bastante gradual, variando em maior ou menor intensidade de acordo com cada morador.

A observação participante é uma técnica amplamente utilizada por pesquisadores que fazem uso de uma abordagem qualitativa no campo da saúde. Pressupõe a inserção do pesquisador no interior do grupo, o que possibilita integração e longa interação com o mesmo. Ocorre o compartilhamento do cotidiano, sendo possível compreender o significado de estar em determinada situação (BRANDÃO, 1981 apud QUEIROZ et al, 2007).

As histórias de vida aqui relatadas foram reconstruídas a partir de fragmentos pouco coerentes, oriundos de depoimentos dos próprios sujeitos, ou de profissionais do CAPS e das RTs. São um esforço na compreensão do percurso que conduziu à institucionalização. Buscando preservar a identidade dos moradores de ambas as RTs, todos os nomes apresentados são fictícios.

Esta pesquisa foi aprovada pelo Comitê de Ética em Pesquisa com Seres Humanos, com o registro CAAE no 06175612.3.0000.0057, conforme a Resolução no 196/96 do CNS, vigente à época de realização do estudo.

\section{Os moradores das Residências Terapêuticas}

\section{Os beneficiários do PVC}

Pedro chegou à RT há seis anos, encaminhado do Sanatório Bahia. Tem 35 anos e passou boa parte da sua vida em orfanatos ou hospitais psiquiátricos. Segundo 
o relato de alguns cuidadores, seu pai, após novo matrimônio, internou-o numa

instituição. Sua madrasta e irmãos nunca foram visitá-lo. É beneficiário do PVC desde 2009. Atualmente, frequenta escola e academia de ginástica, financiada com seu próprio benefício.

Antônia permaneceu internada ininterruptamente no Hospital de Custódia e Tratamento (HCT) durante seis anos e reside na RT também há seis. Tem 59 anos e sua primeira internação foi aos 17. Frequentemente visita seus pais. Mostra-se comunicativa e acolhedora. Vaidosa, gosta de maquiagem, bijuterias, esmaltes etc. Não pratica nenhuma atividade regular fora da RT, mas repetidas vezes diz que gostaria de sair para algum lugar, inclusive de ir à escola.

Janaína esteve durante 18 anos internada no Sanatório Bahia. Há seis vive na RT. Hoje, com 46 anos, é a pessoa com melhor trânsito social da RT. Costuma ir sozinha à padaria, diariamente. Gosta de ficar na janela, talvez observando o movimento da rua. Não conversa muito. Não se sabe nada sobre sua história de vida e quais as circunstâncias que a teriam levado à situação de abandono familiar.

\section{Os beneficiários do $\mathrm{BPC}$}

Augusto tem 58 anos, ficou internado no sanatório durante três e há seis vive na RT. Demonstra comunicação verbal limitada, mas gesticula muito, mostrando os braços, apontando que está arrepiado quando se emociona com alguma situação. Antes das internaçôes, casou-se e tocou em um trio nordestino. Gosta de cantar e tocar sanfona. Também imita movimentos típicos da dança popular do nordeste.

Geraldo tem 45 anos e vive há seis na RT. Embora tenha referência familiar, viveu durante oito anos no Sanatório Bahia sem registro de visitas. Sua família demonstra dificuldade em recebê-lo em definitivo. Mostra-se bastante comunicativo. Atualmente, está matriculado em uma escola regular à noite, à qual vai sozinho.

Rodrigo tem 43 anos e foi internado no Sanatório Bahia aos 12, onde permaneceu durante 25 anos consecutivos. Há seis vive na RT. Não se tem nenhuma informação sobre sua história de vida, nem qualquer referência familiar. Ele é beneficiário do BPC desde 2008. Frequenta uma escola com educação inclusiva, à qual vai diariamente, demonstrando muito entusiasmo. É uma pessoa bastante comunicativa e gosta muito de relógios, de modo que sempre fala sobre eles. 
Paulo ficou internado durante dois anos no Sanatório Bahia, e não se sabe quantas internações anteriores vivenciou, nem o período das mesmas. Tem 44 anos e vive na RT há seis. Normalmente, senta-se nos mesmos lugares dentro de casa e não exibe nenhuma linguagem verbal. Ele demonstra gostar de passear e frequentar o CAPS. Já ajudou na manutenção da horta da RT e, segundo o depoimento de alguns profissionais, alguns aspectos referentes à sua socialização melhoraram bastante. É desconhecida a localização de qualquer pessoa de sua família.

Julieta permaneceu durante três anos internada no Sanatório Bahia. Estava em situação de rua e foi internada quando teve a primeira filha, com quem não teve mais nenhum contato. É natural do interior da Bahia e não tem nenhuma referência familiar. Está com 50 anos e vive há seis na RT. Com exceção das idas ao CAPS, só sai da RT para algum passeio quando é convidada, em companhia de algum responsável. Contudo, recentemente, apresentou vontade de ir à praia e à escola.

Dos 61 anos que Carla já viveu, 38 foram dentro de um hospital psiquiátrico, em sucessivas internações interrompidas nos dias que passava na casa da própria família. Sua mãe é falecida e suas únicas referências familiares são uma tia e uma prima, que moram num bairro próximo à RT, mas que nunca a visitaram ou a receberam em casa. Faz seis anos que ela vive na RT. Segundo sua prima, Carla era uma moça estudiosa, sendo que sua primeira crise ocorreu aos 17 anos, no período em que foi reprovada em uma disciplina na escola. Apresenta uma linguagem de difícil compreensão, mas gosta bastante de conversar e contar seus segredos. Gosta de se enfeitar, costuma fazer penteados diferentes e usar flores no cabelo, colares e brincos coloridos.

Rogério tem 45 anos e permaneceu durante oito internado no Sanatório Bahia. Vive há seis anos na RT e se tornou beneficiário do BPC em 2012. Ele não conversa muito, sempre prefere se sentar no mesmo local, mas se mostra uma pessoa bastante amorosa com a proximidade. Gosta muito de cor-de-rosa.

\section{Os outros: considerações sobre os que não recebem benefício}

Eulália está atualmente com 80 anos. Os últimos 20 desses foram passados dentro do hospital psiquiátrico e seis na RT. Ela gosta de conversar e, às vezes, de escutar músicas de Roberto Carlos. Sobre sua história de vida, conta que durante os anos que viveu no sanatório recebeu apenas uma visita da sua filha. 
Apresenta graves problemas de artrose, que acabam limitando as possibilidades

de realizar atividades sozinha, como tomar banho. Ela se recusa a manter qualquer atividade fora da RT.

Branca viveu durante 35 anos no HCT e vive há cinco na RT. Hoje está com 79 anos. Conversa pouco e demonstra ser uma pessoa reservada. Diz que prefere arrumar a casa. É uma das poucas moradoras que costuma realizar tal atividade cotidianamente.

\section{A utilização do dinheiro}

Nenhum dos moradores das RT recebe os dois benefícios - situação possível, uma vez que são cumulativos. Segundo uma das cuidadoras, metade do recurso que cada pessoa recebe é depositado em poupança e a outra metade é diluída para todo o grupo e utilizada para gastos internos: financiar passeios e comprar pão, roupas, lanches, remédios ou outros materiais necessários.

De acordo com a administração das RTs, isso decorre da insuficiência do recurso transferido pela prefeitura para a manutenção das duas casas: esta se responsabiliza pelo pagamento de contas fixas, como aluguel, luz e água. Além disso, envia semanalmente, para cada RT, um ticket alimentação no valor de 520 reais, que só pode ser utilizado em supermercado.

Não há nenhum financiamento para as necessidades extras, como a compra de remédios não dispensados no SUS, gastos com transporte, lanches ou atividades de ressocialização. Essas despesas, portanto, são custeadas com o recurso do próprio beneficiário. É importante que o morador utilize seu próprio dinheiro para financiar as atividades que deseja realizar e adquirir objetos de interesse, desde que tais ações contribuam para seu desenvolvimento e emancipação.

Embora as poupanças abertas sejam individuais, o dinheiro normalmente é utilizado pelo coletivo, incluindo as duas moradoras que não recebem nenhum benefício. Ele pode ser empregado para despesas maiores, como a realização de algum funeral, a compra de um eletrodoméstico, etc. Não há projetos que trabalhem a poupança enquanto recurso para um futuro retorno à convivência familiar ou, ainda, para o desenvolvimento de um projeto de vida fora da RT. Segundo profissionais do CAPS, os moradores sabem ou foram informados da existência da poupança, embora muitos não consigam dimensionar o seu significado. 
Outro elemento importante diz respeito à forma como o dinheiro é recebido. Sua retirada é feita pelos profissionais do CAPS, e o fato do beneficiário não poder sacá-lo contribui para a construção de fantasias acerca do quanto se ganha e do que poderia ser feito com esse recurso.

Alguns moradores demonstram não saber o valor total do benefício, bem como o que ele poderia pagar. Embora seja preciso relativizar tal situação, levando em consideração as dificuldades que alguns moradores demonstram ter, isso produz consequências importantes. Rogério, por exemplo, acredita que recebe por mês $\mathrm{R} \$ 1200$, quase o dobro do valor do seu benefício. Ele relatou que iria embora da RT se recebesse o valor a que imagina ter direito.

Mesmo considerando que alguns beneficiários possam não ter condições físicas para ir ao banco, como seria o caso de Eulália, para a maioria esse deslocamento seria possível e necessário. Do mesmo modo, a retirada mensal do recurso em banco poderia contribuir para uma melhor tomada de consciência a seu respeito.

Foi possível observar que os moradores recebiam um valor semanal, cuja maior parte ficava em posse do cuidador. Desse modo, os moradores precisavam consultar cuidadores e profissionais do CAPS e obter sua autorização sempre que desejassem comprar algo. Esse controle se mostrava ainda maior quando o item a ser obtido era mais caro, como a situação da dentadura e da sanfona, que serão abaixo relatadas. É fundamental chamar a atenção para a importância de apoiar os beneficiários na utilização do recurso financeiro; contudo, esse suporte deve ser sempre orientado pela intenção de produzir autonomia.

Abaixo estão transcritos dois diálogos que apontam a necessidade de maior apropriação do significado desse dinheiro. As moradoras, em específico, são beneficiárias do PVC:

Pesquisadora: Quanto você ganha?

Beneficiária: 50, 100...

P: E por mês, quanto você ganha?

B: Meu pai disse que é 520 reais, mas eu nunca vi esse dinheiro, não.

P: Esse vestido, foi você que escolheu?

B: Não, foi o cuidador.

P: Você já escolheu algum?

B: Já, com dona...

P: E foi você que pagou? 
P: Você sabe quanto você ganha?

B: Eu não. Tem que tirar para todo mundo, não fica nada para mim.

Algumas situações refletem investimento do CAPS na tentativa de garantir a apreensão do significado do dinheiro. Pedro, por exemplo, que frequenta uma academia de ginástica há alguns meses, em determinados momentos refere que ela é paga pelo seu técnico de referência; em outros, responde que o custeio é realizado com um cartão que lhe pertence. Expõe que recebe dinheiro por mês e faz o número três com as mãos, dando a entender que se trata de 300 reais.

É preciso considerar que há duas pessoas nas RT que não recebem nenhum benefício. Essa ausência de recurso financeiro próprio é amenizada em decorrência da diluição solidária do dinheiro de todos os moradores pelo coletivo. Tal situação apresenta repercussões importantes. Eulália, por exemplo, tem suas necessidades prejudicadas, uma vez que precisa continuamente de remédios que não são dispensados e exames médicos urgentes que o CAPS não consegue marcar com brevidade no SUS.

Muitas pessoas com histórico de longa internação psiquiátrica não possuem qualquer documento civil. A dificuldade em reconstruir a história de vida pregressa dificulta que informaçóes importantes sejam utilizadas para a retirada de novos documentos. Além disso, é uma exigência do PVC que sejam comprovados dois anos ininterruptos de internação, condição que muitas vezes impossibilita o recebimento benefício, uma vez que muitos egressos de hospital psiquiátrico tiveram seus prontuários extraviados, especialmente no caso daqueles oriundos de unidades que foram fechadas.

\section{Situações do cotidiano}

\section{A dentadura}

Durante vários meses, Antônia relatou desejo em implantar uma prótese dentária. Atualmente, ela não tem dentição, o que traz repercussões na sua autoestima e nas possibilidades de comunicação e ingestão de alimentos.

Em uma das visitas, refere que tem economizado para poder comprar a prótese, abrindo mão inclusive de ir ao salão de beleza em prol dessa economia e chegando 
a guardar, segundo ela, a quantia de 500 reais. Em outros momentos, contudo, mostra-se resistente em usar seu próprio dinheiro para esse fim. Embora nessa situação esteja presente uma ambiguidade, ela reflete certo amadurecimento em relação às possibilidades nas quais o próprio dinheiro pode ser gasto.

\section{Salão de beleza, bijuterias e outras bugigangas}

Era comum que o dinheiro recebido representasse para os moradores a possibilidade de aquisição de novos objetos ou serviços. Antônia, por exemplo, sempre expressava sua vontade de ir ao salão de beleza ou de pintar o cabelo para cobrir os fios brancos que surgiam. Durante a coleta de dados não foi observada nenhuma ida ao salão, mas o tingimento do cabelo costumava ocorrer na própria RT. Mesmo sem o estímulo à circulação pelo espaço amplo da cidade, essa atividade pode aumentar a autoconfiança e fortalecer aspectos relacionados à feminilidade.

$\mathrm{O}$ benefício às vezes era utilizado para presentear alguém. Antônia referiu levar compras ou dinheiro para a casa de seus pais. A possibilidade de presenteálos ou ajudar nas despesas de casa pode contribuir para o fortalecimento do vínculo familiar, uma vez que o ato de ofertar e receber aparentava estar imbuído de afetividade.

Foi possível observar que, em alguns momentos, a escolha do pertence a ser comprado não era realizada pelo próprio morador. Em uma das visitas realizadas, Antônia mostrou em sua bolsa dois desodorantes do tipo "A" e em seguida revelou que não gostava daquela marca, que o cuidador teria escolhido. Esclareceu que preferia os do tipo “B”. Ao mesmo tempo, Geraldo e Rodrigo mostraram as sandálias que, segundo eles, as cuidadoras elegeram. Considera-se que a escolha dos próprios produtos de higiene pessoal ou dos demais pertences possibilita um maior empoderamento e sentimento de autocuidado.

\section{A sanfona}

Por Antônio ter sido sanfoneiro no passado, foi-lhe perguntado se ele gostaria de ir a uma loja de instrumentos para comprar uma sanfona. Ele respondeu "amém". Em dezembro de 2010, foi iniciado o trabalho para a compra do instrumento, mas esse processo só foi retomado em 2011. Importante considerar que, durante a realização de alguns orçamentos, Antônio não esteve presente. 
Sua técnica de referência solicitou aos cuidadores que saíssem com ele para fazer uma nova estimativa de preço e eleger a sanfona. Entre o agendamento do dia de compra e sua efetivação transcorreram alguns meses. Antônio foi à loja junto com os cuidadores e, segundo relatos desses, não apenas escolheu o instrumento, como reconheceu outros que estavam à mostra na loja, tendo conversado com o vendedor sobre eventos de sua própria vida.

A situação envolvendo a compra da sanfona aponta para alguns elementos importantes. Nesse caso, o dinheiro foi utilizado também para resgatar um pouco da história de vida de Antônio, além de lhe proporcionar momentos de lazer. Contudo, é possível observar a presença de entraves no processo de aquisição do instrumento, que demorou meses até ser obtido.

\section{O relógio}

O primeiro benefício que Rogério recebeu foi sacado junto da assistente social do CAPS. Após recebê-lo, ele entrou em uma loja e ficou observando os relógios expostos. Sinalizou a preferência por um específico, cor-de-rosa. A profissional, considerando as dificuldades de Rogério em se comunicar, foi sensível o suficiente para perceber a situação e comprou o relógio com ele.

A utilização do dinheiro pode servir para a aquisição de itens de desejo dos moradores, de forma a estimular sua capacidade de escolha e sua responsabilidade sobre a manutenção e o cuidado com aquilo que se adquire. A situação acima aponta, ainda, para a necessidade de que o profissional de saúde mental seja capaz de se comunicar para além da linguagem verbal dos beneficiários, adentrando o idioma pessoal de cada um (SAFRA, 2004).

\section{Passeios pela cidade}

Alguns dos passeios que ocorrem na RT com os moradores são determinados pelos cuidadores. Eles decidem o local e qual morador irá participar da atividade. Segundo depoimento do cuidador, costuma-se alugar um carro, pago com os benefícios. Tal situação retira não apenas a autonomia dos moradores de decidir para onde ir, mas também a possibilidade de negociação, aspecto fundamental para o desenvolvimento pessoal e a melhoria da convivência.

Além disso, praticamente inexistem passeios para locais próximos, que explorem o potencial do bairro. Os cuidadores relatam que tais atividades já 
ocorreram de forma mais frequente, inclusive durante a noite, tornando-se escassas na atualidade. Eles consideram que sua autonomia diminuiu quando a gestão das RTs passou a ser da Secretaria Municipal de Saúde de Salvador. Em momento anterior, elas eram administradas por uma instituição filantrópica.

Essas atividades de saída da RT, que podem parecer ações exclusivas de lazer, são fundamentais porque promovem uma maior apropriação do bairro. Sugere-se que tais ações sejam realizadas preferencialmente de ônibus, o que potencializaria o aprendizado acerca da forma de utilização do transporte público, além de promover uma maior aproximação com a comunidade, a qual poderá passar a ocupar um papel de facilitadora do complexo processo de desinstitucionalização.

Outra situação diz respeito à ida de lojistas à RT. Tal conduta favorece que o morador escolha a própria roupa, mas continua perpetuando uma situação de restrição àquele espaço físico. Do mesmo modo, eram comuns situações em que os moradores expressavam desejos de ir, por exemplo, à pizzaria. Os cuidadores, contudo, relataram que normalmente as pizzas eram pedidas, entregues e consumidas na própria RT.

\section{PVC, BPC e desinstitucionalização: algumas consideraçôes}

Embora não seja um benefício voltado unicamente para pessoas com transtornos mentais, o BPC também objetiva a habilitação e a reabilitação destas, além de promover sua integração à vida comunitária. Portanto, é relevante considerar sua importância não apenas no que diz respeito à garantia das condições materiais de existência, mas também à proteção social que ele oferece e à possibilidade de aumento da autonomia. O BPC é um aliado da Reforma Psiquiátrica Brasileira, especialmente quando esse direito é conquistado por pessoas mais fragilizadas do ponto de vista econômico e social.

O PVC, contudo, é voltado exclusivamente para egressos de longa internação psiquiátrica. O manual do programa estima que cerca de 15.000 pessoas em todo o Brasil poderiam ser contempladas (BRASIL, 2003). Todavia, em todo o território nacional existem apenas 3.961 beneficiários (BRASIL, 2012). São 108 beneficiários na Bahia, sendo que 24 desses residem em Salvador. Importante ressaltar que, de acordo com depoimentos de profissionais da Secretaria Estadual de Saúde da Bahia, calcula-se que, em todo o estado, mais de 500 pessoas ainda 
vivam em instituições psiquiátricas ou de asilamento. Tal conjuntura demonstra o frágil desenvolvimento desse programa.

Apesar de ter sido identificada uma Comissão de Acompanhamento na Secretaria Municipal de Saúde de Salvador, alguns profissionais do CAPS relataram que os contatos com a mesma são escassos ou inexistem. Além disso, segundo uma das integrantes dessa comissão, não há comunicação com o nível estadual. É desconhecida qualquer comissão da Secretaria Estadual de Saúde da Bahia que esteja voltada especificamente para o gerenciamento do PVC, embora o manual do programa preveja sua existência. Embora o número de beneficiários se mostre muito aquém do possível, o referido programa está inserido no processo da Reforma Psiquiátrica e apresenta um significativo avanço para o processo de desinstitucionalização de pessoas com longo período de internação psiquiátrica.

Goffman (1974) esclarece que, se o período de internamento é muito longo, quando o sujeito retornar para o mundo exterior, poderá estar temporariamente incapaz de enfrentar alguns aspectos de sua vida diária. Desse modo, é preciso salientar que, mesmo os moradores das RTs apresentando um estado de cronificação em decorrência da longa internação, um trabalho continuado com eles não só é primordial, como produziria uma maior autonomia em vários aspectos, inclusive no que se refere ao uso do dinheiro.

Seria preciso empreender uma ação permanente que objetivasse trabalhar não apenas a utilização desse recurso financeiro, mas também a aquisição do empoderamento e a construção de uma existência mais criativa. Embora seja possível notar algumas conquistas dos moradores no que se refere ao uso do dinheiro, não foram identificados trabalhos persistentes dessa natureza nas duas RTs.

É preciso considerar que na utilização do dinheiro está em jogo uma dimensão da clínica que rejeita a separação entre concreto e simbólico e admite que elementos materiais podem fazer parte de um projeto terapêutico singular. Essa perspectiva amplia as possibilidades do fazer terapêutico, transformando elementos do cotidiano em agentes potenciais de transformação. O dinheiro, nesse caso, precisa ser usado, por exemplo, para ajudar o sujeito a conseguir sustentar a permanência de um objeto, a melhorar sua autoimagem, a reconstruir sua própria história, seus laços sociais e seus projetos de vida. Além disso, uma série de elementos de gestão contribuem para que a realidade observada nas duas RTs visitadas precise de avanços no que se refere à utilização do dinheiro. É importante considerar que as 
chamadas "estratégias de desinstitucionalização" preveem apenas a existência das RTs e o acesso ao PVC, deixando de considerar a necessidade urgente de outras medidas que possibilitem uma efetiva reapropriação da vida.

Embora a desinstitucionalização não esteja afirmada enquanto objetivo na lei que institui o PVC, é necessário ressaltar que um programa que objetiva contribuir "efetivamente" para o processo de inserção social de egressos de longa internação psiquiátrica não pode se limitar ao repasse de recurso financeiro. Essa transferência precisa ser o início de uma estratégia a ser construída por gestores, profissionais e beneficiários, e não um fim em si mesma. Muitos profissionais do CAPS apontaram que, em termos ideais, o PVC precisaria agregar outras estratégias que garantissem efetivamente não apenas a saída do hospital psiquiátrico, mas a reapropriação da vida e, especialmente, o retorno ao convívio familiar.

É preciso considerar ainda a alta demanda de atendimento para os CAPS, onde a quantidade de pacientes é frequentemente superior à real possibilidade para ofertar um atendimento minucioso, gradativo e de altíssima complexidade, como o que os moradores das RTs necessitam. Logo, também é necessária a ampliação dos recursos humanos nesses serviços.

O contexto estudado se agrava diante da atual conjuntura da atenção à saúde mental em Salvador, onde é ainda insuficiente o número de CAPS e outros dispositivos que compõem a Rede de Atenção Psicossocial. Segundo a Secretaria Estadual de Saúde da Bahia, a cidade, apesar de ter quase três milhões de habitantes, não conta com nenhum CAPS III e apenas dois CAPS i. Além disso, faltam Centros de Convivência e Equipes de Consultório de/na Rua. A Estratégia de Saúde da Família tem uma cobertura de apenas 17\% e a quantidade de Núcleos de Apoio à Saúde da Família ainda se mostra extremamente incipiente.

A ausência de uma rede fortalecida e articulada composta por serviços de atenção à saúde e de assistência social e por dispositivos de cultura e lazer deixa nas mãos dos CAPS a responsabilidade para a realização solitária do complexo trabalho de desinstitucionalização. Os CAPS, apesar de seu imenso potencial, precisam de maior apoio para a realização dessa proposta, incluindo ações de educação permanente e supervisão clínica, dadas as circunstâncias nas quais estão sobrevivendo na referida cidade. Desse modo, embora as RTs e os benefícios como BPC e PVC sejam inegáveis progressos, essas estratégias ainda precisam 
progredir de modo a proporcionar a autonomia e o empoderamento necessários para que a desinstitucionalização efetivamente ocorra.

\section{Considerações sobre o trabalho do cuidador}

A partir do trabalho de campo, foi observada nos cuidadores uma baixa motivação para o exercício laboral, o que prejudicava o seu bom desenvolvimento. Como aponta Furtado (2006), os novos dispositivos em saúde mental requerem profissionais eticamente alinhados aos princípios da Reforma Psiquiátrica e tecnicamente formados para a sustentação de novas formas de atenção. É nessa perspectiva que se torna urgente ter um olhar atento no que diz respeito ao trabalho do cuidador no espaço dos SRTs.

São desconhecidos documentos que especifiquem qual o papel desse profissional, de modo que as tarefas cotidianas ganham contornos de acordo com as características da pessoa que as exerce. Além disso, a fragilidade de investimentos em educação permanente e no cuidado para com a saúde dos cuidadores produz dificuldades na compreensão do propósito das atividades sugeridas pelos profissionais do CAPS.

São comuns nos CAPS assertivas de que o cuidador deve ser um acompanhante do morador, a fim de promover o máximo desenvolvimento de sua autonomia. Contudo, esse ideal de cuidado parece distante, à medida que o próprio cuidador é responsável pela administração da casa, realizando tarefas de limpeza, compras etc. Isso sem falar das questôes relacionadas ao vínculo de trabalho precário, do salário baixo e dos atrasos recorrentes no seu pagamento.

É preciso considerar que há uma desvalorização do papel do cuidador no processo de desinstitucionalização. Normalmente são pessoas que trabalharam durante anos em hospitais psiquiátricos e que, por falta de qualificação, acabam por reproduzir nas RTs uma realidade manicomial. Os cuidadores são o elo primordial na relação entre a cidade e a casa, de modo que também precisam de cuidados e investimentos.

Considerando que as ações de desinstitucionalização, dada sua complexidade, exigem um intenso investimento humano de todos que atuam na saúde mental, inclusive dos cuidadores, é preciso garantir melhores condições de trabalho, constantes atividades de educação permanente, supervisão clínica e cuidado, a fim 
de potencializar a qualidade da assistência em saúde mental. O desafio, portanto, é reconstruir as possibilidades de uma prática transformadora, com foco na qualidade e singularidade do cuidado, na qual seja possível reinventar vidas para além do diagnóstico e do sintoma (ROTELLI, 1990 apud DIMENSTEIN, 2004).

\section{Limites encontrados e recomendações}

O presente trabalho encontra seu limite no perfil de moradores encontrados nas duas RTs, os quais apresentavam dificuldades em narrar a própria história de vida ou mesmo de discorrer sobre os projetos para o futuro. Tal contexto inviabilizou a realização de entrevistas com os beneficiários e restringiu o estudo aos dados de observação acerca do cotidiano.

Há ainda um número restrito de pesquisas que abarquem a temática da utilização de benefícios pelos egressos de longa internação psiquiátrica. Sugerese a realização de investigações futuras acerca dessa temática, inclusive com beneficiários que não residam em RT, uma vez que não foi possível localizá-los. Também devem ser criados estudos com beneficiários que apresentem menores níveis de cronificação.

Aconselha-se a investigação mais aprofundada das concepções que os profissionais e gestores atribuem a esse programa, a fim de buscar identificar os possíveis entraves para sua concretização e ampliação.

\section{Considerações finais}

Embora seja uma política compensatória, o PVC é uma estratégia de desinstitucionalização na medida em que pode auxiliar no desmonte do manicômio e do lugar instituído para a loucura, a partir da transformação do sujeito-asilado em sujeito-autônomo. Mais do que para a recuperação de habilidades e competências, o programa deve ser empregado para estimular a autonomia dos sujeitos, considerada a base para a desinstitucionalização, juntamente com a transformação cultural da sociedade. Caso contrário, cairá em um assistencialismo que apenas tenta remediar, sem sucesso, os efeitos de anos de exclusão.

É preciso que sejam criados programas e açôes que invistam cotidianamente no fortalecimento da vinculação entre a família e o beneficiário, a fim de possibilitar o retorno ao lar. Ainda, é necessário potencializar as ações de apropriação da casa 
e da cidade, a inserção no mercado de trabalho, assim como o fortalecimento da

rede social de apoio, especialmente para aqueles que não têm nenhuma referência de família. ${ }^{1}$

\section{Referências}

AMARANTE, P. O homem e a serpente: outras histórias para a loucura e a psiquiatria. Rio de Janeiro: Fiocruz, 1996. 142p.

- Sobre duas proposições relacionadas à clínica e à reforma Psiquiátrica. In: QUINET, A. (Org.). Psicanálise e psiquiatria: controvérsias e convergências. Rio de Janeiro: Rios Ambiciosos, 2001. p. 103-119.

BASAGLIA, F. As instituições da violência. In: BASAGLIA, F. (Org.). A instituiçãa negada: relato de um hospital psiquiátrico. Rio de Janeiro: Graal, 1985. p. 99-135.

Saúde/doença. In: AMARANTE, P; CRUZ, L.B. (Org.). Saúde mental, formação e crítica. Rio de Janeiro: LAPS, 1996. p. 17-36.

BRASIL. Senado Federal. Constituição da República Federativa do Brasil. Brasília: Senado Federal, 1988.

Ministério da Saúde. Secretaria de Atenção à Saúde. Departamento de Ações Programáticas Estratégicas: Manual do Programa "De Volta para Casa”. Brasília: Ministério da Saúde, 2003. 18 p.

Ministério da Saúde. Lei n.o 10.216, de 06 de abril de 2001. Dispóe sobre a proteção e os direitos das pessoas portadoras de transtornos mentais e redireciona o modelo assistencial em saúde mental. Diário Oficial [da] Republica Federativa do Brasil, Brasília, DF, p. 2, 6 abr. 2001. Seção 1.

- Ministério da Saúde. Mostra Fotográfica Programa De Volta para Casa: cartilha de monitoria. Brasília: Ministério da Saúde, 2008. 32p.

- Ministério da Saúde. Portaria 3.088, de 23 de dezembro de 2011. Institui a Rede de Atenção Psicossocial para pessoas com sofrimento ou transtorno mental e com necessidades decorrentes do uso de crack, álcool e outras drogas, no âmbito do Sistema Único de Saúde. Diário Oficial [da] República Federativa do Brasil, Brasília, DF, n. 251, p. 59, nov. 2011. Seção 1.

- Ministério da Saúde. Saúde Mental em Dados - 10, ano VII, no 10. Informativo eletrônico. Brasília: 2012. Disponível em <www.saude.gov.br>. Acesso em: 13 nov. 2012. 28 p. BIRMAN, J. Sexualidade na instituição asilar. Rio de Janeiro: Achiamé, 1980. 54 p.

CAMPOS, I.O. Programa de Volta para Casa em um município do estado de São Paulo: suas possibilidades e limites. 2008. 113p. Dissertação (Mestrado em Enfermagem Psiquiátrica) Escola de Enfermagem, Universidade de São Paulo, Ribeirão Preto, 2008. 
DIMENSTEIN, M. A reorientação da atenção em saúde mental: sobre a qualidade e humanização da assistência. Psicol. cienc. prof. Brasília, v. 24, n. 4, dez. 2004. Disponível em <http://pepsic.bvsalud.org/scielo.php?script=sci_arttext\&pid=S141498932004000400013\&lng=pt\&nrm=iso >. Acesso em: 18 nov. 2012.

FURTADO, J.P. Avaliação da situação atual dos Serviços Residenciais Terapêuticos no SUS. Ciênc. saúde coletiva, Rio de Janeiro, v. 11, n. 3, set. 2006. Disponível em <http:// www.scielo.br/scielo.php? script=sci_arttext $\&$ pid $=$ S1413-81232006000300026\&lng $=$ en $\&$ $\mathrm{nrm}=\mathrm{iso}>$. Acesso em: $05 \mathrm{dez} .2013$.

FURTADO, J.P. et al. Inserção social e habitação: um caminho para a avaliação da situação de moradia de portadores de transtorno mental grave no Brasil. Interface. Botucatu, v. 14, n. 33, jun 2010. Disponível em <http://www.scielo.br/scielo.php?script=sci_arttext\&pid=S1414$32832010000200012 \& \operatorname{lng}=\mathrm{en} \& \mathrm{nrm}=$ iso $>$. Acesso em: $05 \mathrm{dez} .2013$.

GOFFMAN, E. Manicômios, prisões e conventos. São Paulo: Perspectiva. 1974.320 p.

LANCETTI, A. Clinica peripatética. São Paulo: Hucitec, 2009. 127p.

LIMA, S.C. O Programa de Volta para Casa em Fortaleza: o que mudou na vida de seus beneficiários. 2008. 129p. Dissertação (Mestrado em Políticas Públicas e Sociedade) Centro de Humanidades, Universidade Estadual do Ceará, Fortaleza, 2008.

LOBOSQUE, A.M. Princípios para uma Clínica Antimanicomial. São Paulo: Hucitec, 1997. $96 \mathrm{p}$.

LOUGON, M. Psiquiatria Institucional: do hospício à reforma psiquiátrica. Rio de Janeiro: Fiocruz, 2006. 226p.

MÂNGIA, E.F.; ROSA, C.A. Desinstitucionalização e Serviços Residenciais Terapêuticos. Rev. Ter. Ocup. Univ. São Paulo, v. 13, n. 2, p. 71-7, 2002. Disponível em: http://www. revistas.usp.br/rto/article/view/13899.. Acesso em: 07 dez. 2013.

OLIVEIRA, V.L. Estranha. In: No coração da boca. São Paulo: Escrituras, 2006. 74p.

PANDE, M.N.R.; AMARANTE, P.D.C. Desafios para os Centros de Atenção Psicossocial como serviços substitutivos: a nova cronicidade em questão. Ciênc. saúde coletiva, Rio de Janeiro, v. 16, n. 4, abr. 2011. Disponível em: <http://www.scielo.br/scielo.php?script=sci_ arttext \&pid=S1413-81232011000400006\&lng=pt\&nrm=iso $>$. Acesso em: 18 nov. 2012. QUEIROZ, D.T. et al. Observação participante na pesquisa qualitativa: conceitos e aplicações na área da saúde. R Enferm UERJ, Rio de Janeiro, v. 15, n. 2, p. 276-283, 2007. RIBEIRO, I.P. De Volta para Casa: estudo com egressos de hospitais psiquiátricos. 2006. 97p. Dissertação (Mestrado em Psicologia da Saúde) - Universidade Metodista de São Paulo, São Bernardo do Campo, 2006. 
SAFRA, G. A pó-ética na clínica contemporânea. Aparecida, SP: Ideias\&Letras, 2004. 160 p.

SILVA, M.V.O. A instituição sinistra: mortes violentas em hospitais psiquiátricos no Brasil. Brasília: CFP, 2001. 398p.

TENÓRIO, F. A psicanálise e a clinica da reforma psiquiátrica. Rio de Janeiro: Rios Ambiciosos, 2001b. 168 p.

. Da reforma psiquiátrica à clinica do sujeito In: QUINET, A. (Org.). Psicanálise e

psiquiatria: controvérsias e convergências. Rio de Janeiro: Rios Ambiciosos, 2001a. p. 212-131.

\section{Nota}

${ }^{1}$ S.S. Lima participou da idealização, planejamento e condução da atividade que deu origem à pesquisa; realizou coleta, análise e interpretação dos dados; revisão bibliográfica e elaboração do manuscrito. S.A. Brasil participou das atividades de idealização, planejamento e orientação da pesquisa; contribuiu na análise e interpretação dos dados; auxiliou na revisão bibliográfica e realizou revisão crítica do manuscrito. Não houve financiamento para a realização deste trabalho e não há conflito de interesses. 


\section{Abstract}

From the Back Home Program to the achievement of autonomy: pathways required for the actual process of deinstitutionalization The Back Home Program [Programa De Volta Para Casa - PVC] aims to contribute to the social integration of people who were hospitalized at least two consecutive years in a psychiatric hospital. This research aims to identify the impact of PVC, as well as the Continuous Benefit (BPC) to implement deinstitutionalization actions. For six months were used participant observation in two Therapeutic Residences located in SalvadorBA, Brazil, including informal conversations with professionals in these areas, as well as from the Center for Psychosocial Care (CAPS). We also carried out research of official documents relating to PVC. Data collected on daily routine in Residences suggest that there is bureaucratization and low autonomy on the use of money, besides the lack of effective strategies for the development of empowerment of PVC beneficiaries. There is a need for greater investment in continuing education for professionals, as well as significant strengthening of the so-called "Deinstitutionalization Strategies" provided by the Network for Psychosocial Care.

Key words: institutionalization; Mental Health; health policy; development of programs; deinstitutionalization. 